\title{
Carbothermic Reduction by Microwave Heating
}

\author{
Marcelo Breda MOURÃO, Ivan Parreiras de CARVALHO JR. and Cyro TAKANO
}

University of São Paulo, Escola Politecnica, Department of Metallurgical and Materials Engineering. Av. Prof. Mello Moraes, 2463, Cidade Universitaria, CEP 05508-900, Sao Paulo, S.P. Brazil. E-mail: cytakano@usp.br and mbmourao@usp.br

\begin{abstract}
The carbothermic reduction of iron ores is the most important reaction in ironmaking and has been performed mainly in the Blast Furnace. In the last years, several new processes have been proposed as alternatives, and many types of reactors have been tested. The most promising processes are those in which a mixture of iron ore and carbonaceous material is heated at high temperatures, promoting the reaction with formation of metallic iron. It became clear that one of the main obstacles to a fast reaction is heat transfer from the surroundings to the core of the mixture. On the other hand, several studies have shown that microwave heating is very effective in some industrial processes, like drying and sintering of ceramics. In the microwave heating, the material is heated from the inside, thus avoiding the constraints of heat transfer from the surroundings to the inner part of the material. In this work, microwave heating has been applied to the carbothermic reduction of hematite. The obtained results have shown that it is possible to heat iron ore-carbon mixtures above the reduction temperature, and the reaction rates have been compared to those obtained employing conventional heating with the same mixtures.
\end{abstract}

KEY WORDS: microwave energy; carbothermic reduction; composite pellets

\section{Introduction}

High temperature carbothermic reduction of iron ore in the form of composite pellets is a very effective way of obtaining metallic iron. Due to the generation of the reducing gas (carbon monoxide) inside the pellet, the mass transport step in the gaseous phase is greatly enhanced, and the overall reaction area is much higher than in the conventional reduction of iron ore pellets by external gases. The reaction has to be performed at high temperatures and, as it is an endothermic reaction, with a high heat load. In this way, heat transport from the surroundings to the pellet surface and then heat conduction from the surface to the inner parts of the pellet become one of the main controlling steps. If the heat needed by the reaction could be generated inside the pellet, the overall reaction rate could be faster. This goal can be achieved with microwave heating.

Microwave radiation can penetrate and propagate through several dielectric materials, generating electric fields that induce the motion of free or bound charges; the resistance to these motions due to inertial, elastic and frictional forces causes losses and, as a consequence, the heating of the material.

As pointed out by Ghoreshy and Pickles ${ }^{1}$ microwave heating provides potential advantages when applied to pyrometallurgical process, viz.;

- the heat is generated inside the material and thus no heat transfer from the energy source is needed;
- only the material itself is heated, and the temperature of the refractory is minimized;

- the energy source is relatively clean, easily controlled and no combustion gases are generated; the gas volume in the reactor is reduced;

- both endothermic and exothermic reactions can be promoted;

- there is considerable potential for improved working conditions as compared to conventional processes.

Microwave heating has been applied successfully to several processes, like drying (food, pigments, ceramics, fabric, chemicals), food processing, fiber curing, tar recycling, toxic wastes disposal, pharmaceuticals, oil heating, radioactive wastes treatment, rubbers, etc $^{2}$

Zhong et $\mathrm{al}^{3}$ studied the reduction of a low-silica taconite concentrate by coke or coal using an industrial microwave generator at $2.45 \mathrm{GHz}$ and a power output up to $15 \mathrm{~kW}$. They concluded that microwave energy dissipates rapidly throughout the volume of the material and heats it directly, solving the "cold center" problem; a significant increase in the reduction rate was obtained compared to a conventional heating system; with $20 \%$ excess stoichiometric carbon, a $90 \%$ reduction of iron ore was achieved in 10 minutes, with a temperature greater than $1000^{\circ} \mathrm{C}$; they obtained a highly reduced iron and a dust-free gas.

Ghoreshy and Pickles ${ }^{1}$ employed a domestic microwave oven (Samsung $900 \mathrm{~W}, 2.45 \mathrm{GHz}$ ) to study the 
processing of mixtures of electric arc furnace dust and carbon as a reductant. They reported that the electric arc furnace dust exhibits excellent coupling with microwaves, attaining $1250^{\circ} \mathrm{C}$ after 10 minutes processing. Also, they observed that the size of the carbon particle affects the coupling: carbon of +12 mesh attains $1100^{\circ} \mathrm{C}$ after 10 minutes, whereas carbon -200 mesh attains $950^{\circ} \mathrm{C}$ after the same time. They concluded that electric arc furnace dust can be successfully processed in a microwave furnace, the products being a zinc oxide rich dust and an iron rich residue.

Morita and Sano 4 studied the carbothermic reduction of steelmaking slags in a microwave furnace $(2.45 \mathrm{GHz}, 1600$ W). They obtained a temperature of $1787^{\circ} \mathrm{C}$ in 7 minutes, with an iron yield of $90 \%$; they showed that the heating rate increased with the increase in the amount of carbon in the mixture.

\section{Experimental Procedure}

The materials employed in the present investigation were:

- $\quad$ iron ore, containing $69 \mathrm{wt} \%$ total iron, $0.94 \mathrm{wt} \%$ silica, $0.35 \mathrm{wt} \%$ alumina and $0.014 \mathrm{wt} \%$ phosphorus; the particle size was under 150 mesh.

- $\quad$ coke fines, with $91.94 \%$ of fixed carbon, $7.5 \%$ ashes and $0.56 \%$ sulfur; two different particle sizes were employed: between 100 and 150 mesh, and between 35 and 50 mesh (named "coarse coke" in this paper)

- $\quad$ charcoal fines, with $61.65 \%$ fixed carbon, $5.47 \%$ ashes and 32.88 volatile matter; particle size under 150 mesh.

- $\quad$ Portland cement, composed of $64.3 \mathrm{wt} \% \mathrm{CaO}, 19.05$ wt $\% \mathrm{SiO}_{2}, 4.92$ wt $\% \mathrm{Al}_{2} \mathrm{O}_{3}$; particle size under 150 mesh.

Composite pellets were hand made after mixing the ore with cement and the carbonaceous material in an intensive mixer (Turbula), and with water. Before the experiment the pellets were dried, weighted and measured.

The weight of the pellets were in the range 4-6 g. The amount of carbonaceous material (coke or charcoal) added to the mixture were calculated based on the amount of combined oxygen in the iron ore; two different relations between the amount of carbonaceous material and combined oxygen were used: $\mathrm{C} / \mathrm{O}=1.0$ and $\mathrm{C} / \mathrm{O}=1.33$, for both coke and charcoal, where " $\mathrm{C}$ " represents the mass of carbonaceous material. It is to be noted that the same mass of coke or charcoal contains different amounts of fixed carbon and volatile matter, but the criteria of same mass was adopted trying to keep similar conditions of heating for both materials.

A microwave oven of $2.45 \mathrm{GHz}$ frequency and $1100 \mathrm{~W}$ power were used. The dimensions of the cavity were of the same order of magnitude of the wave length $(12.2 \mathrm{~cm}$ in the present case); this fact can lead to uneven distribution in the cavity. In this way, the pellets were always positioned in the same spot.

A cylindrical hole was made from the surface to the center of each pellet, in order to allow a thermocouple (S type) to be inserted in a way that the tip of the thermocouple was positioned near the center of the pellet.
The pellets were placed over an insulation mantle and covered by a glass protection, in which an argon flow of 2 $1 /$ min was used during the experiments.

In order to obtain each set of results, different pellets were submitted to microwave energy during previously determined periods of time, after which their weight was measured. In some cases, the pellets were wrapped with an insulation mantle. Pellets of the same composition of the ones used in the experiments with microwave energy were also reduced upon heating in an electric resistance furnace, for comparison purposes.

\section{Ovencavity \\ 2 Gass protection \\ 3. Sample \\ 4. Insulation \\ 5. Therroouple \\ 6. Argon in \\ 7. Gesaut}

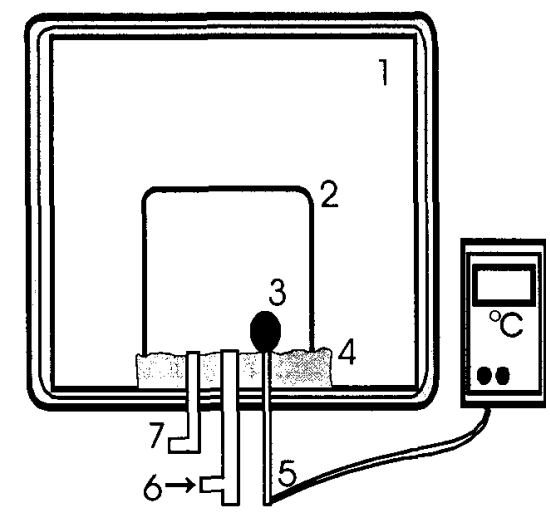

Fig. 1: Schematic of the experimental set up employed in this work.

\section{Results}

Figure 2 shows the results obtained in several experiments in terms of percent reaction as a function of time, for the various types of pellets tested. Figure 3 shows the temperature measured inside the pellets as a function of time. It can be seen that there is a close relationship between temperature and reaction rate: pellets that present higher reaction rate also present higher rates of temperature increase. Figure 3 shows also that, when no thermal insulation is used, the temperature increases sharply up to a certain level, and then it remains approximately constant. The maximum temperature attained is a function of a balance between the amount of heat generated inside the pellet and the heat consumed by the reaction plus the heat transferred to the surroundings. The lowest temperature attained was for pellets containing coke, with no cement. The addition of cement $(6.5 \mathrm{wt} \%)$ to the mixture increases the maximum temperature attained by about $250 \mathrm{~K}$. As a consequence, the fraction reacted after 30 minutes increased from 0.42 to 0.74 . This is an indication that the cement is more easily heated by microwave radiation than the iron oxides. Among the iron oxides, it is reported that magnetite is the one more susceptible to microwave heating ${ }^{3}$.

The increase in the amount of coke also increases the maximum temperature attained: for pellets with cement, the increase in the amount of coke from $\mathrm{C} / \mathrm{O}=1.0$ to $\mathrm{C} / \mathrm{O}=$ 1.33 increased the maximum temperature by about $100 \mathrm{~K}$, increasing the fraction reacted at 30 minutes from 0.74 to 0.80 .

The use of coarse coke, other parameters maintained the same, causes a higher heating rate at the early stages, but the maximum temperature attained is very 
similar to the one attained with the finer coke. This fact reflects in the reaction rate, that is faster at the early stages, but the reacted fraction at 30 minutes is very similar for both particle sizes. The particle size of the carbonaceous material affects the reaction rate in two ways: for coarse particles, the increase in temperature is faster and the final temperature is higher, and the reaction rate thus tends to be higher; on the other hand, the coarser the particle, there is less surface area available for the reaction, and the reaction rate tends to be lower. In this way, probably exists one optimum particle size that maximize the reaction rate, as pointed out by Lorenson et $\mathrm{al}^{5}$.

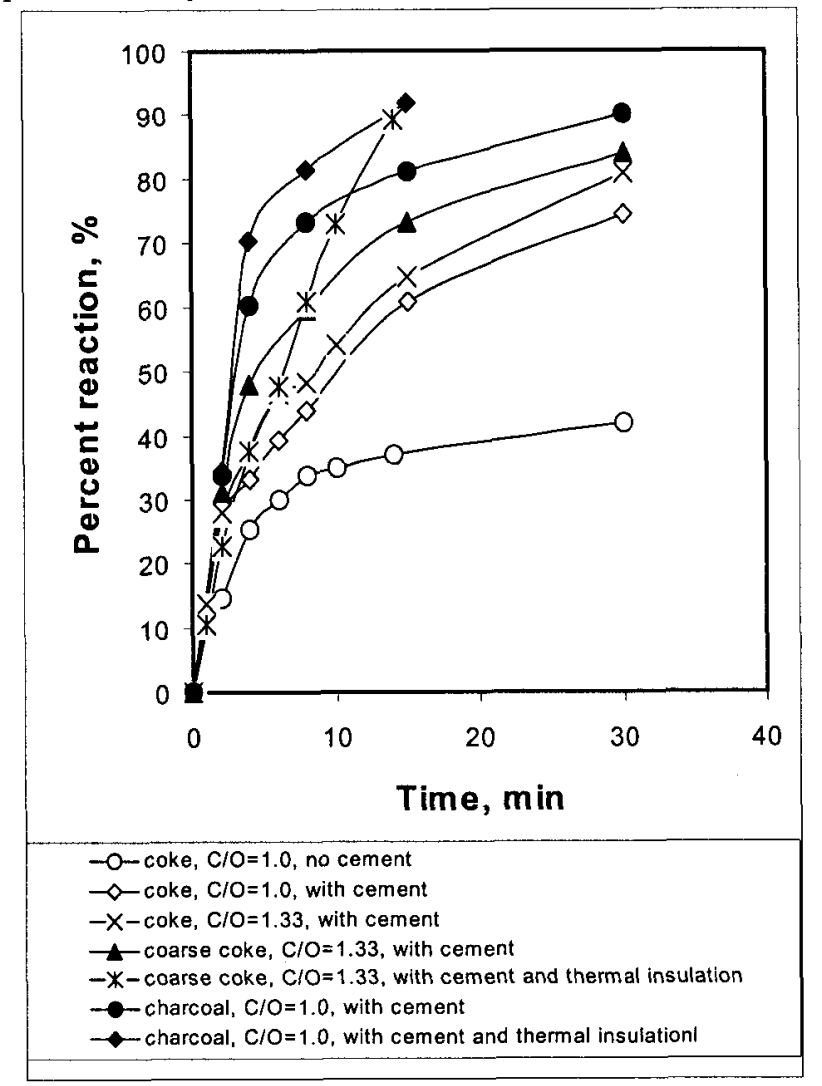

Fig. 2: Percent reaction as a function of time and type of pellet when the pellets are submitted to microwave heating.

When the results obtained for pellets containing charcoal and cement are compared to the ones obtained with pellets containing coke and cement, for the same $\mathrm{C} / \mathrm{O}$ relation, it can be seen that the heating rate is higher for the charcoal bearing pellets, and that the temperature after 30 min is about $200 \mathrm{~K}$ higher than in the coke bearing pellets; the percent reaction of the charcoal bearing pellets attained $90 \%$, whereas those with coke attained $75 \%$. The higher heating rate of charcoal as compared to coke probably is related to the higher content of volatile matter in charcoal; Chatterje and Misra ${ }^{6}$ have shown that the dielectric constant is higher for coals of low ranking.

As the temperature of the pellets depends on the heating rate and the rate of heat transferred to the surroundings, the use of thermal insulation around the pellets could lead to higher temperatures, and hence to higher reaction rates. Experiments were performed in which pellets containing cement and charcoal or coke were wrapped with an insulation mantle, and the results showed that at the first minutes there is little difference between pellets with or without insulation, but after some time the temperature is higher in the insulated pellets. This resulted in $90 \mathrm{~K}$ higher for the insulated charcoal bearing pellets as compared to the non-insulated pellet, after $15 \mathrm{~min}$, resulting in $92 \%$ reaction against $81 \%$ reaction; for coke bearing pellets the difference between insulated and non insulated pellets were even higher: after 15 minutes, insulated pellets presented $90 \%$ reaction and $1140{ }^{\circ} \mathrm{C}$, against $73 \%$ reaction and $1005^{\circ} \mathrm{C}$ for non insulated pellets. The effect of the thermal insulation is more pronounced in coke bearing pellets than in charcoal bearing pellets due to several factors: the higher thermal conductivity of coke, the lower chemical reactivity, which implies in a lower reaction rate, and the lower heating rate of coke as compared to charcoal under microwave radiation. Together, these factors lead to a more pronounced beneficial effect of the thermal insulation in coke bearing pellets, which is reflected in the shape of the curves for this kind of pellet in figures 2 and 3.

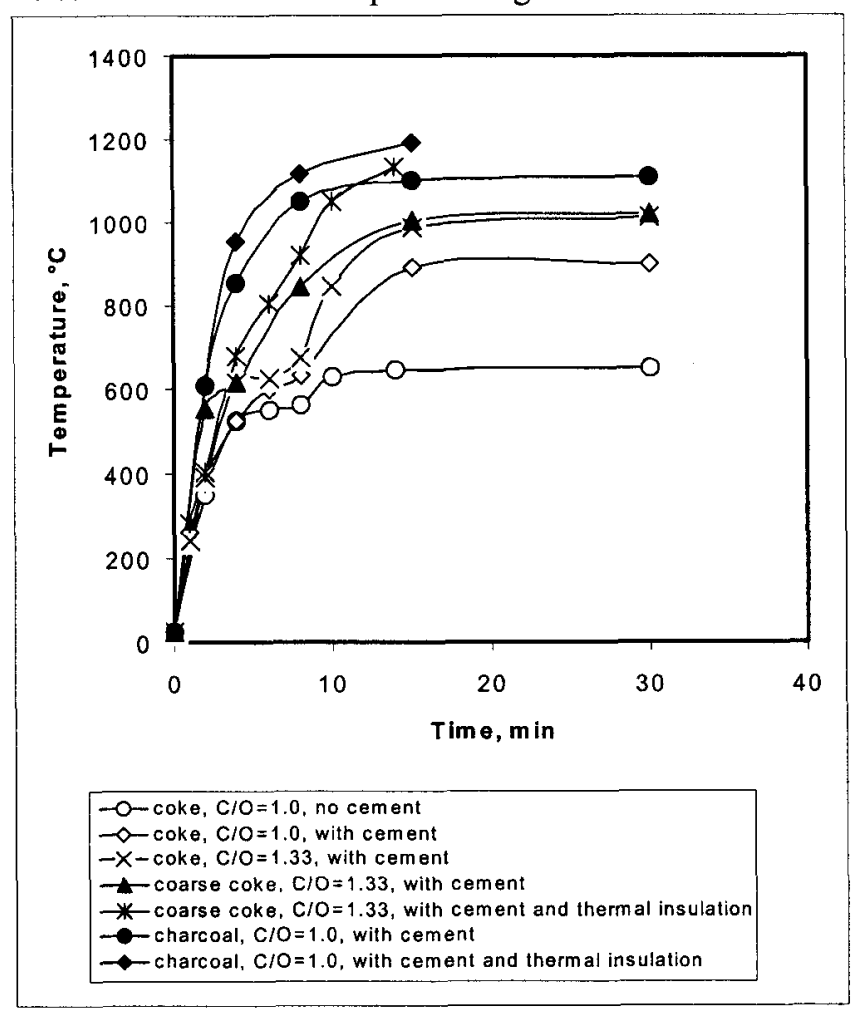

Fig. 3: Temperature as a function of reaction time and type of pellet when the pellets are submitted to microwave heating.

Figure 4 presents a comparison of results obtained with microwave heating with results of percent reaction as a function of time obtained when the pellets were heated in an electric resistance furnace. For this comparison, the best and the worst result obtained with microwave heating, respectively, insulated pellets containing charcoal and cement and pellets containing coke, with no cement or insulation, are compared with equivalent pellets submitted to heating in an electric resistance furnace, the one with charcoal at $1150^{\circ} \mathrm{C}$ and the one with coke heated to $950^{\circ} \mathrm{C}$.

It is to be noted that in the experiments performed in the electric resistance furnace the sample was submitted to the furnace temperature at the beginning of the experiment, whereas in the microwave oven the sample temperature 
increased from room temperature to the final temperature during the experiment. For instance, for the experiment with coke showed in figure 4 , after 6 minutes the sample temperature was $550^{\circ} \mathrm{C}$, after 10 minutes, $629^{\circ} \mathrm{C}$ and after 30 minutes, $648^{\circ} \mathrm{C}$, that is much less than the $950^{\circ} \mathrm{C}$ of the electric resistance furnace, and also well below the temperature at which the solution loss reaction (Boudouard reaction) occurs under conventional heating. Besides this fact, the reaction rate for the coke pellets in the microwave oven was higher than in the electric resistance furnace, although in both cases the reaction rate was relatively low. Presently, there is no explanation why the reaction can occur at such a low temperature; Hassine et $\mathrm{al}^{7}$ report the decrease in the reaction temperature under microwave heating for the production of tantalum carbide by carbothermic reduction of tantalum oxide.

Regarding the experiments with charcoal bearing pellets showed in figure 4 , the reaction rate at $1150^{\circ} \mathrm{C}$ in the electric resistance furnace was very similar to the reaction rate of the same type of pellet in the microwave oven, up to approximately $70 \%$ reaction; at this point, the rate in the microwave oven started to decrease. This fact was attributed to the depletion of the charcoal; the criteria used to calculate the amount of charcoal, based on total amount instead of the amount of fixed carbon, lead to the deficiency of carbon at the final steps of reaction. As the carbonaceous material is much more susceptible to microwave heating than the iron ore, in the final steps of reaction the amount of charcoal probably is not enough to maintain the same heat input as in the beginning of reaction; in the heating by the electric resistance furnace, this phenomenon does not occur.

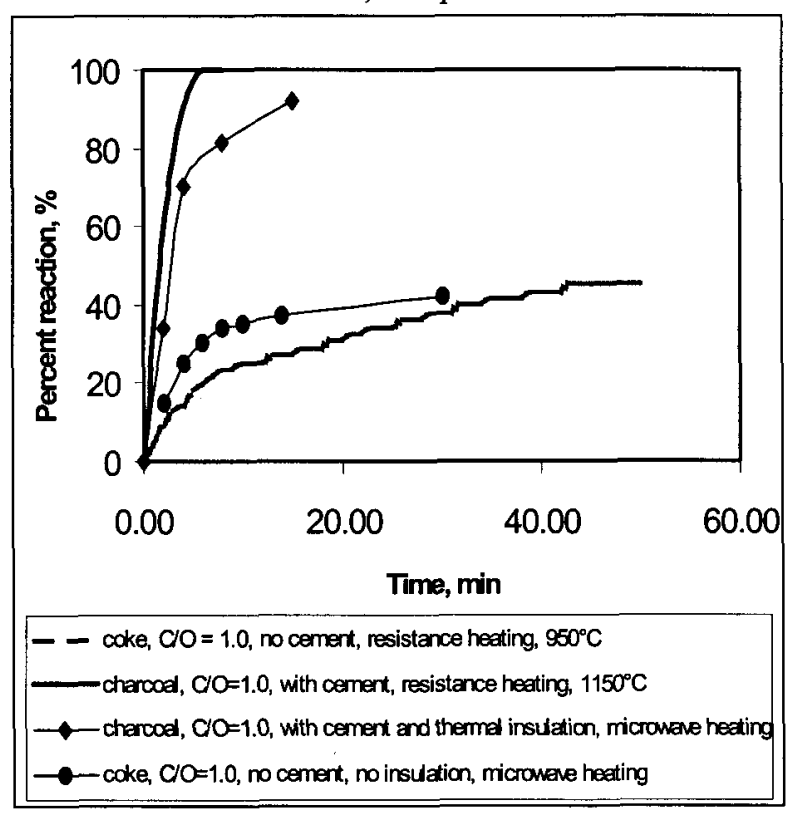

Fig. 4: Comparison of the results of the percent reaction as a function of time for microwave heating and conventional heating.

\section{Conclusions}

The experimental results obtained in the present study lead to the following conclusions:

- Microwave radiation could furnish the energy needed to the carbothermal reduction of iron ore in the form of composite pellets;

- The reaction rate is faster and the attained temperature is higher when cement is added to the composite pellets;

- Pellets containing charcoal as a reductant reacts faster than the ones containing coke, as a result of the higher temperature attained;

- The increase in the amount of carbonaceous material promotes higher reaction rates, and higher temperatures;

- Thermally insulated pellets attain higher temperature than non-insulated pellets, and consequently thermal insulation promotes a higher reaction rate;

- Reaction rates of pellets under microwave radiation are competitive to those obtained in conventional heating.

\section{Acknowledgements}

The authors would like to thank FAPESP (The São Paulo State Foundation to Research Support) for financial support to this work.

\section{REFERENCES}

1) M. Ghoreshy, and C.A. Pickles: 1994 Electric Furnace Conf. Proc., (1994) 187.

2) Microdry Corp., Industrial Microwave Processing, (1987).

3) S. Zhong,, H.E. Geotzman and R.L Bleifuss: Minerals and Metallurgical Processing, November (1996), 174.

4) K. Morita and N. Sano: Global Symp. on Recycling, Waste Treatment and Clean Techn., vol. II, Rewas (1999), 1583.

5) C.P. Lorenso, M.C.L. Patterson, G. Risto and R. Kimber: MRS Symp. Proc., vol. 269 (1992), 129.

6) I. Chatterje and M.:Misra: MRS Symp. Proc., vol. 189 (1991) 195.

7) N. A. Hassine, J.G.P. Binner and T.E. Cross: Int. J. of Refractory Metals \& Hard Materials, vol. 13 (1985) 353. 